\title{
Life-history theory provides a framework for detecting resource limitation: a test of the Nutritional Buffer Hypothesis
}

\author{
Brett R. Jesmer (D) , 1,2,3,4,11,12 Matthew J. Kauffman (D) ${ }^{1,5}$ Alyson B. Courtemanch (D) ${ }^{6}$ Steve Kilpatrick, ${ }^{7}$ \\ Timothy Thomas, ${ }^{8}$ Jeff Yost, ${ }^{9}$ Kevin L. Monteith, ${ }^{1,2,10}$ and Jacob R. Goheen ${ }^{1}$ \\ ${ }^{1}$ Program in Ecology, Department of Zoology and Physiology, University of Wyoming, Laramie, Wyoming 82071 USA \\ ${ }^{2}$ Wyoming Cooperative Fish and Wildlife Research Unit, Department of Zoology and Physiology, University of Wyoming, Laramie, \\ Wyoming 82071 USA \\ ${ }^{3}$ Center for Biodiversity and Global Change, Yale University, New Haven, Connecticut 06520 USA \\ ${ }^{4}$ Department of Ecology and Evolutionary Biology, Yale University, New Haven, Connecticut 06520 USA \\ ${ }^{5}$ U.S. Geological Survey, Wyoming Cooperative Fish and Wildlife Research Unit, Department of Zoology and Physiology, University of \\ Wyoming, Laramie, Wyoming 82071 USA \\ ${ }^{6}$ Wyoming Game and Fish Department, P.O. Box 67, Jackson, Wyoming 83001 USA \\ ${ }^{7}$ Wyoming Wild Sheep Foundation, P.O. Box 666, Cody, Wyoming 82414 USA \\ ${ }^{8}$ Wyoming Game and Fish Department, P.O. Box 6249, Sheridan, Wyoming 82801 USA \\ ${ }^{9}$ Colorado Parks and Wildlife, P.O. Box 775777, Steamboat Springs, Colorado 80487 USA \\ ${ }^{10}$ Haub School of Environment and Natural Resources, University of Wyoming, Laramie, Wyoming 82072 USA
}

Citation: Jesmer, B. R., M. J. Kauffman, A. B. Courtemanch, S. Kilpatrick, T. Thomas, J. Yost, K. L. Monteith, and J. R. Goheen. 2021. Life-history theory provides a framework for detecting resource limitation: a test of the Nutritional Buffer Hypothesis. Ecological Applications 31(4):e02299. 10.1002/eap.2299

Abstract. For ungulates and other long-lived species, life-history theory predicts that nutritional reserves are allocated to reproduction in a state-dependent manner because survival is highly conserved. Further, as per capita food abundance and nutritional reserves decline (i.e., density dependence intensifies), reproduction and recruitment become increasingly sensitive to weather. Thus, the degree to which weather influences vital rates should be associated with proximity to nutritional carrying capacity - a notion that we refer to as the Nutritional Buffer Hypothesis. We tested the Nutritional Buffer Hypothesis using six moose (Alces alces) populations that varied in calf recruitment (33-69 calves/100 cows). We predicted that populations with high calf recruitment were nutritionally buffered against the effects of unfavorable weather, and thus were below nutritional carrying capacity. We applied a suite of tools to quantify habitat and nutritional condition of each population and found that increased browse condition, forage quality, and body fat were associated with increased pregnancy and calf recruitment, thereby providing multiple lines of evidence that declines in calf recruitment were underpinned by resource limitation. From 2001 to 2015, recruitment was more sensitive to interannual variation in weather (e.g., winter severity, drought) and plant phenology (e.g., duration of spring) for populations with reduced browse condition, forage quality, and body fat, suggesting these populations lacked the nutritional reserves necessary to buffer demographic performance against the effects of unfavorable weather. Further, average within-population calf recruitment was determined by regional climatic variation, suggesting that the pattern of reduced recruitment near the southern range boundary of moose stems from an interaction between climate and resource limitation. When coupled with information on habitat, nutrition, weather, and climate, life-history theory provides a framework to estimate nutritional limitation, proximity to nutritional carrying capacity, and impacts of climate change for ungulates.

Key words: Alces alces; diet quality; Keigley live-dead index; kidney fat index; nitrogen limitation nutritional carrying capacity; nutritional ecology; plant phenology; pregnancy; recruitment

Manuscript received 12 February 2020; revised 10 July 2020; accepted 6 October 2020. Corresponding Editor: N. Thompson Hobbs.

${ }^{11}$ Present address: Department of Fish and Wildlife Conservation Virginia Tech Blacksburg Virginia 24061 USA

${ }^{12}$ E-mail: brettjesmer@vt.edu

\section{INTRODUCTION}

Ungulates employ a conservative life-history strategy, wherein adults prioritize survival over reproduction (Stearns 1992, Gaillard et al. 1998). This life-history paradigm predicts that a sequence of density-dependent declines in vital rates occurs as populations approach carrying capacity (Eberhardt 2002, Bonenfant et al. 
2009): declines first manifest in juvenile survival, then age of first reproduction and pregnancy, and last in adult survival (Fig. 1A). Although population growth is most sensitive to adult survival, survival of adults is relatively invariant (Gaillard et al. 1998), often causing recruitment and other vital rates early in life to drive variability in population growth (Gaillard et al. 2000, Raithel et al. 2007). Density-independent factors (i.e., weather), however, interact with density-dependent (i.e., per capita forage availability) forces and cause populations experiencing strong resource limitation to be more sensitive to severe weather conditions (Coulson et al. 2001, Bowyer et al. 2014, Monteith et al. 2014a), except in instances where density dependence overwhelms the effect of weather (Stewart et al. 2005, Bowyer et al. 2014). Thus, life-history theory provides a potentially useful lens through which proximity to carrying capacity can be viewed.

The energy and nutrients that ungulates acquire (i.e., their nutritional condition) dictates their demography and, ultimately, population growth (Keech et al. 2000, Cook et al. 2004, Monteith et al. 2014a). Nutritional
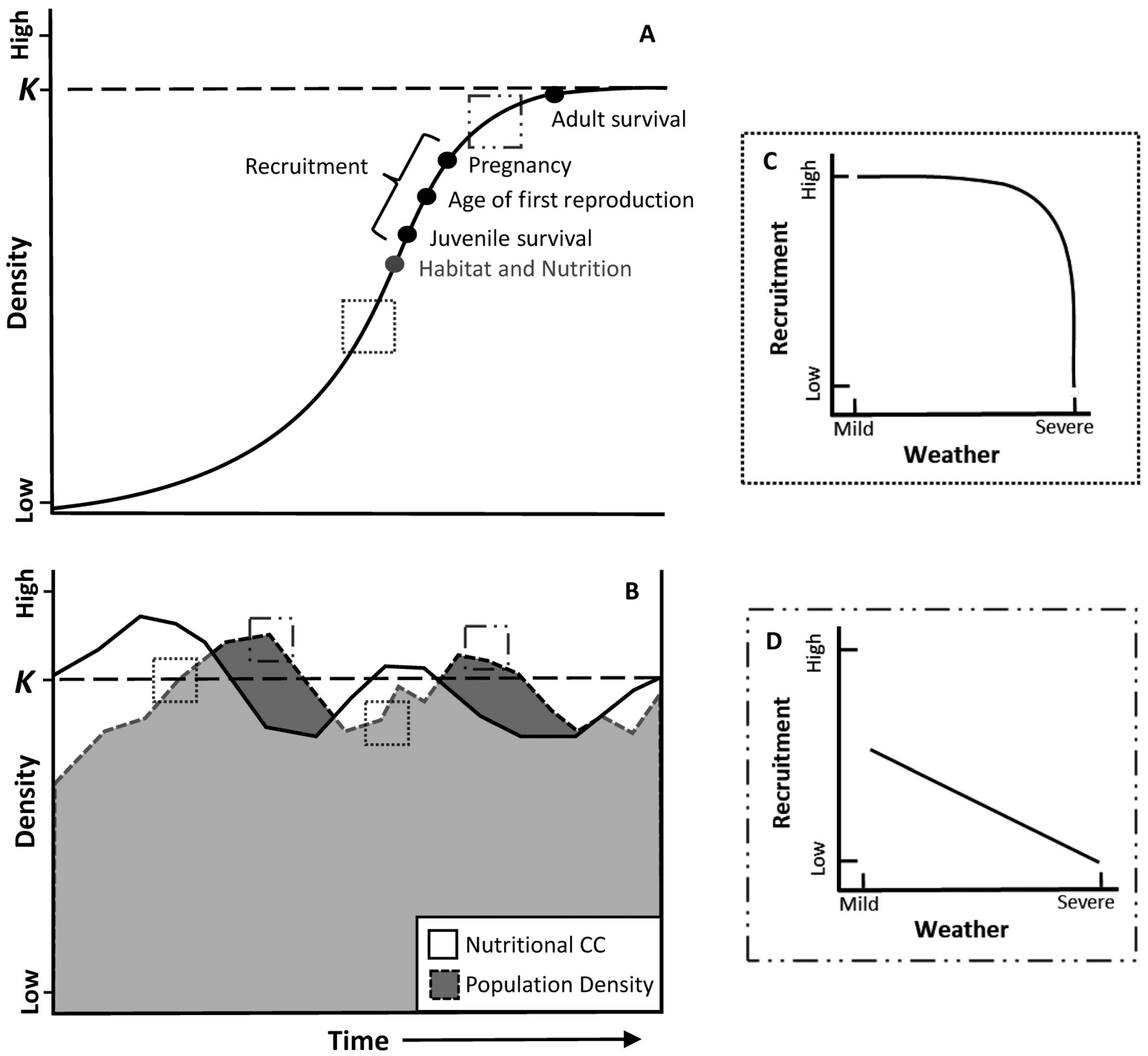

FIG. 1. Conceptual figure illustrating (A) the life history paradigm for long-lived vertebrates (black text; Bowyer et al. 2000, Eberhardt 2002, Bonenfant et al. 2009), wherein a sequence of declines in life-history traits are expected to occur as populations approach carrying capacity $(K)$, and (B) the dynamism of nutritional carrying capacity (white polygon) and its contrast to population density (gray polygon) and ecological carrying capacity ( $K$; horizontal dashed line; McCullough 1999). When a population is below nutritional carrying capacity ( $\mathrm{C}$; dotted boxes), individuals have ample nutritional reserves; causing recruitment and other vital rates to be buffered from the negative effects of severe weather. In contrast, when populations are at or above nutritional carrying capacity ( $\mathrm{D}$; dashed boxes), individuals have relatively few nutritional reserves and vital rates are sensitive to severe weather conditions. Panel A has been modified to include habitat and nutrition (gray text) as factors that influence variation in life history, thereby providing a 'management paradigm' for large herbivores. 
condition of individuals therefore provides a direct link between environmental conditions and life-history characteristics, and thus population growth (Parker et al. 1999, Parker et al. 2009). Extending Eberhardt's (2002) life-history paradigm to include nutritional condition leads to the dual predictions that (1) habitat should deteriorate before declines in nutritional condition because of nutritional carryover (Harrison et al. 2011, Monteith et al. 2014a) and (2) both habitat and nutritional condition should decline before declines in recruitment and other vital rates (Fig. 1A). Thus, measures of habitat and nutritional condition should underpin demographic changes, thereby linking resource limitation to the lifehistory characteristics of ungulates.

Ecological carrying capacity is defined as a state of equilibrium between the size of a consumer population and its resources (Fig. 1A; McCullough 1979, MacNab 1985). Although valuable as a heuristic, ecological carrying capacity is difficult to quantify because the quantity and quality of resources are ever changing. The concept of nutritional carrying capacity, however, recognizes that equilibrium is rarely achieved because the quantity and quality of forage vary across temporal scales (e.g., seasonally, annually, over decades; Mautz et al. 1978, McLeod 1997, McCullough 1999; Fig. 1B). Because nutritional condition integrates both density-dependent and density-independent factors, nutrition provides a lens through which the environmental conditions experienced by a population can be viewed (Parker et al. 2009). The influence of nutritional condition on population dynamics of ungulates should be especially evident in the absence of strong top-down forcing (i.e., predation or disease; Coulson et al. 2001, Bowyer et al. 2014, Monteith et al. 2014a). Wildlife ecologists have therefore come to appreciate that the negative impacts of severe weather can be mitigated by ensuring population densities are below nutritional carrying capacity, where greater nutritional reserves buffer vital rates from the effects of severe weather (Fig 1C, D; Bowyer et al. 2000, 2014) - a notion we refer to as the Nutritional Buffer Hypothesis. Thus, the degree to which weather influences vital rates should be associated with proximity to nutritional carrying capacity.

Across much of their southern range, moose (Alces alces) populations are experiencing suppressed recruitment and population declines (Murray et al. 2006, Lenarz et al. 2010, Monteith et al. 2015, Ruprecht et al. 2016). A number of factors have been implicated in these declines, including reduced forage quality and changes in plant phenology (Monteith et al. 2015), heat stress (Lenarz et al. 2009), parasites and disease (Murray et al. 2006, Musante et al. 2010, Henningsen et al. 2012), and predation (Severud et al. 2015). In the Intermountain West of North America, calf recruitment has declined over the last 30 years (Fig. 2; Monteith et al. 2015). For populations inhabiting the Greater Yellowstone Ecosystem, predation of calves by grizzly bears (Ursus arctos horribilis) and wolves (Canis lupus) has contributed to declines in calf recruitment (Oates et al., unpublished manuscript). Nevertheless, nearby populations outside of the Greater Yellowstone Ecosystem that lack grizzly bears and wolves also have declined (Fig. 2), suggesting that a more widespread mechanism is responsible.

Calf recruitment across the Intermountain West is variable and site specific (Fig. 2), and such variation may reflect interactions between climate and forage conditions (Bowyer et al. 2014). Recent (past 30 to $70 \mathrm{yr}$ ) colonization and translocation of moose across the Intermountain West (i.e., Wyoming, Idaho, Montana, and Utah; Brimeyer and Thomas 2004, Toweill and Vecellio 2004, Wolfe et al. 2010, DeCesare et al. 2014, Jesmer et al. 2018) has likely contributed to among-population variation in the quantity, quality, and composition of forage because both current and past herbivory alter forage characteristics (Augustine and McNaughton 1998, Anderson et al. 2007). For example, herbivory, temperature, precipitation, and plant phenology influence digestibility, protein content (i.e., nitrogen concentration), and biomass of forage (Bryant et al. 1992, Pettorelli et al. 2005b, Post et al. 2008, Seaton et al. 2011, Craine et al. 2012). Variation in calf recruitment across the Intermountain West therefore provides a means to assess the Nutritional Buffer Hypothesis and thereby evaluate how density-dependent and density-independent factors combine to determine nutritional carrying capacity.

We tested the Nutritional Buffer Hypothesis, which predicts that populations exhibiting high levels of calf recruitment were either (1) experiencing favorable climatic conditions or (2) were below nutritional carrying capacity wherein the effects of weather conditions were mitigated by abundant forage and nutritional reserves. We developed a suite of field, laboratory, and remotesensing tools to evaluate the potential density-dependent and density-independent drivers of ongoing declines in moose recruitment across part of their southern range boundary. By integrating a widely available tool set with the life-history paradigm for long-lived species, we offer a conceptual and methodological framework that will help guide future research approaches and facilitate data-driven management decisions (Fig. 1).

\section{Methods}

\section{Study area}

We studied six populations of moose across Wyoming, northern Colorado, and northern Utah, USA (Fig. 2). Habitats were characterized by riparian shrublands dominated by Booth's willow (Salix boothii), Geyer's willow (Salix geyeriana), and planeleaf willow (Salix planifolia). Within riparian shrublands, several other willow species, deciduous shrubs (e.g., family Rosaceae and Betula glandulosa), cottonwoods (Populus spp.), and several grasses (family Poaceae), sedges (Carex spp.), and forbs (e.g., families Asteraceae, Onagraceae) also were 

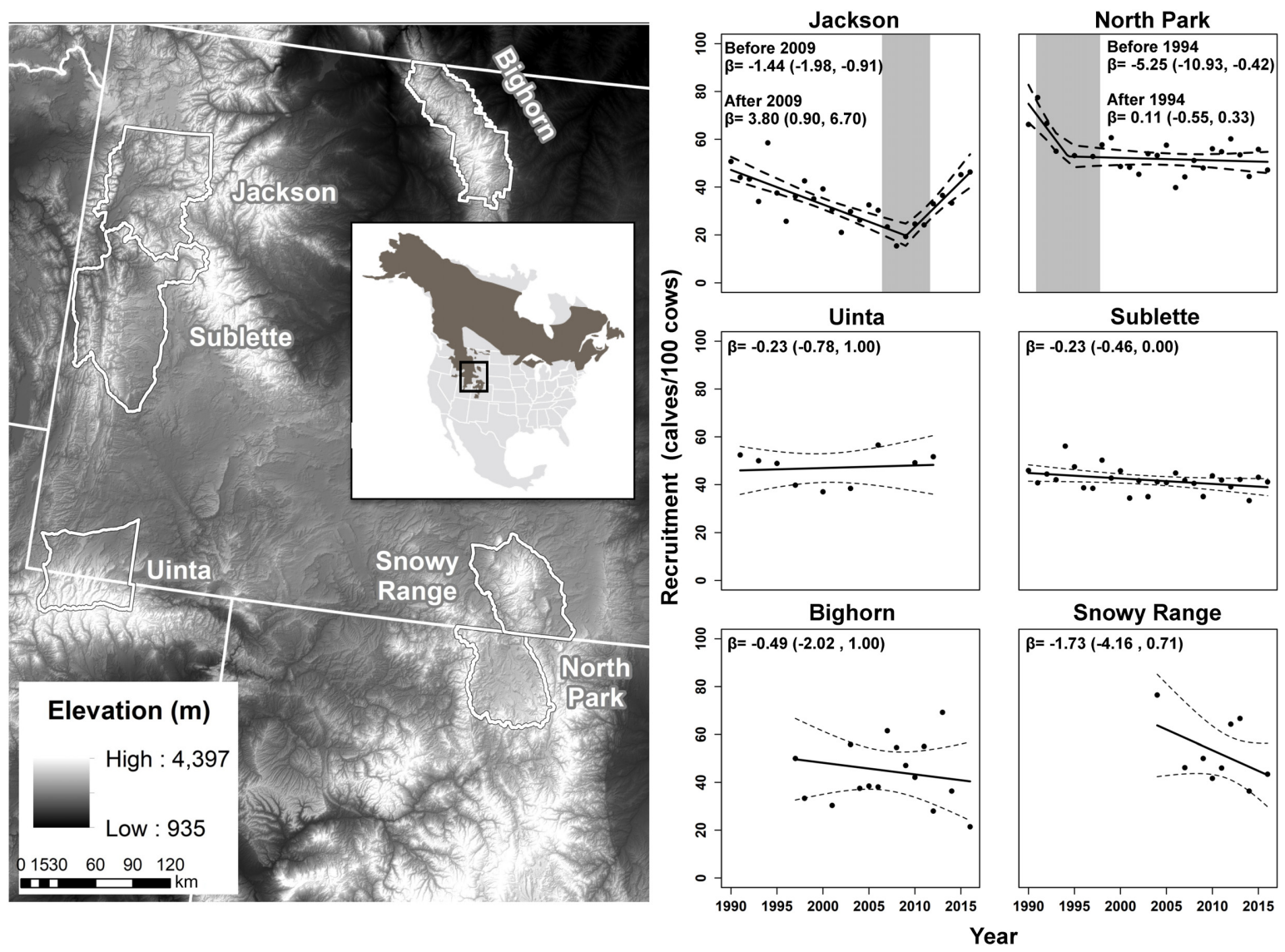

FIG. 2. Study region (left) and trends in calf recruitment (calves/100 cows) from 1990-2016 across the study area (right). Solid and dashed lines represent trends and their $95 \%$ confidence intervals. Vertical gray rectangles illustrate $95 \%$ confidence intervals for a change in slope estimated from piecewise regression. $95 \%$ confidence intervals for slope coefficients $(\beta)$ are in parentheses.

common. Moose also used habitats with interspersed riparian habitats (hereafter "uplands"; Becker 2008, Baigas et al. 2010) characterized by mixed conifers (Abies lasiocarpa, Picea engelmannii, Pinus contorta, Pseudotsuga menziesii), aspen (Populus tremuloides), sagebrush (Artemisia spp.), mountain mahogany (Cercocarpus spp.), and bitterbrush (Purshia tridentata). Winters were characterized by deep snow (mean February snow depth $78 \pm 15 \mathrm{~cm}$ ) and cold temperatures (mean February low temperature $-15^{\circ} \pm 1{ }^{\circ} \mathrm{C}$ ), whereas summers were characterized by low precipitation (mean July rainfall $4 \pm 1 \mathrm{~cm}$ ) and mild temperatures (mean July high temperature $23^{\circ} \pm 2^{\circ} \mathrm{C}$; Western Regional Climate Center).

\section{Study design and sampling}

Moose space use.-To quantify forage quantity, diet quality, and weather and climatic conditions across the six study populations, we estimated the spatial distribution of moose for each population in both winter and summer by parameterizing a random forest predictive model (Breiman 2001, Liaw and Wiener 2002, Evans et al. 2011) with $>1.5$ million GPS collar locations, land cover, and topographic variables. We then reclassified the probability of use surface to only include high probability of use areas (i.e., the 0.5 quartile) and used these maps to constrain spatially balanced, random stratified sampling (Stevens and Olsen 2004, Kincaid et al. 2012) of forage quantity and diet quality (see Forage quantity and diet quality). The predicted spatial distribution of moose was also used to constrain the area within each population's range from which weather and climate data were extracted. These weather and climate data were then used to quantify the relationship between spatiotemporal variation in weather and calf recruitment (see Climate, weather, and phenology). See supplementary materials (Appendix S1) for detailed random forest methodology.

Climate, weather, and plant phenology.-We used a time series of remotely-sensed plant greenness (Normalized Difference Vegetation Index [NDVI]; MODIS product MOD09Q1; $250 \times 250 \mathrm{~m}$ pixel size, 8-d temporal resolution), DayMet products (Thornton et al. 2014; $1 \times 1 \mathrm{~km}$ pixel size), and the Palmer Drought Severity Index (PDSI; Abatzoglou et al. 2014.; $4 \times \sim 4 \mathrm{~km}$ pixel size) 
to quantify spatially and temporally explicit weather, climate, drought, and phenology patterns. Within high probability of use areas, climate, weather, and drought were summarized for winter, spring, summer, and autumn seasons separately. We defined seasons using measures of plant phenology rather than calendar dates by fitting a double logistic function to annual patterns of NDVI (i.e., plant phenology; Bischof et al. 2012). Fitting double logistic curves to annual patterns of plant phenology also allowed us to estimate the date at which the instantaneous rate of green-up (IRG) peaked and thereby estimate the timing of peak forage quality across each population (Hebblewhite et al. 2008; see Appendix S1 for detailed methodology). Within each season, we estimated metrics of plant phenology important to ungulates: (1) length of spring as the number of days between the start and end of spring, (2) length of the growing season as the number of days between start of spring and start of autumn, and (3) plant biomass by summing NDVI values throughout the growing season (i.e., integrated NDVI; Pettorelli et al. 2005a, 2007). Integrated NDVI measures the cumulative photosynthetic activity (i.e., plant biomass) of moose forage in open habitats (e.g., willow and wetland habitat), whereas NDVI primarily measures the photosynthetic activity of the tree canopy in forested habitats and may therefore not be an accurate measure of forage biomass for moose in closed habitats (Borowik et al. 2013). However, our spatial distribution model constrained our sampling of NDVI primarily to open canopy willow and wetland habitats, meaning integrated NDVI is a valid proxy for forage biomass in this study. Using DayMet products, we estimated daily minimum and maximum temperature, and cumulative precipitation and snow water equivalence for each season in each study area. We estimated drought severity as the cumulative annual PDSI values within each seasonal range and study area. For each metric we averaged the daily or cumulative sum of values to obtain population level estimates of environmental conditions.

Forage quantity and diet quality.-To quantify forage quantity and diet quality we measured the condition of key browse species and quantified the amount of nitrogen in feces collected from individual moose. We divided high probability of use areas into "core habitat" (defined as the 0.75 quartile), and "peripheral habitat," which we defined as the $0.50-0.75$ quartile. Because willow is the primary forage for moose across the Intermountain West (Renecker and Schwartz 2007, Baigas 2008, Vartanian 2011; Jesmer et al. 2020), we restricted sampling to core and peripheral habitat areas occupied by willow (i.e., riparian habitat) using the National Landcover Database (Homer et al. 2015). Next, within each management unit (see Fig. 2), we identified 20 locations within core habitat and 20 locations within peripheral habitat using a spatially balanced, stratified random sampling algorithm (Stevens and Olsen 2004, Kincaid et al. 2012). At each location, we randomly selected a direction that allowed us to remain within riparian habitat for $200 \mathrm{~m}$ and surveyed a transect along which we assessed browsing intensity via the Keigley "live-dead index" (Keigley and Fager 2006). Each transect consisted of 20 individual willow plants spaced $10 \mathrm{~m}$ apart. The live-dead index quantifies browsing intensity by measuring the difference in height between the tallest stem killed by browsing and the height of the base of the tallest current year's growth on an individual willow plant. Within transects, negative live-dead values reflect willow patches that are being browsed at a rate that will lead to their death, halt future recruitment of willow, and offer little forage for herbivores. Positive values indicate that willow patches are growing despite herbivory, and thereby reflect the amount of biomass available for removal by herbivores (Keigley and Fager 2006). Thus, the index serves as a proxy for the number of browsers in an area relative to the amount of available browse and browse growing potential (driven by soil, water, nutrients, weather, etc.), making the index well suited for studies of resource limitation.

To quantify diet quality, we measured the nitrogen content of fecal samples (see Laboratory methods) collected along transects on both summer and winter ranges. In winter, we collected fecal samples along browse-condition transects in riparian habitat and opportunistically in upland habitats (e.g., aspen and conifer forests, sagebrush, and other xeric shrub communities). In summer, we constrained sampling to core habitat and used spatially balanced stratified random sampling to collect fecal samples within riparian habitat and upland habitat strata (Jesmer et al. 2020). We identified 20 locations within each stratum, and at each location we randomly selected a direction that allowed us to remain within the habitat strata for the entire $2-\mathrm{km}$ sampling transect. We used detection dogs to find fecal samples along transects during summer because fecal samples were scattered across vast summer ranges, hidden by thick vegetation, and needed to be no more than $\sim 48 \mathrm{~h}$ old for DNA analysis (Dahlgren et al. 2012). During winter, visual detection of fecal samples was feasible because feces were concentrated on winter ranges, conspicuous, and frozen in snow. All samples were collected according to a sterile protocol to prevent cross contamination and placed in a $-20^{\circ} \mathrm{C}$ freezer within $8 \mathrm{~h}$.

Recruitment.-Calf recruitment was estimated via aerial surveys by biologists from the Wyoming Game and Fish Department, Colorado Parks and Wildlife, and Utah Division of Wildlife Resources. Biologists classified populations by sex and age class between December and February when moose were aggregated on snow-covered winter ranges. Surveys were focused in areas of riparian, deciduous, and conifer habitat. Ground surveys were sometimes used to augment aerial survey data for small populations when large numbers of females were not observed during aerial surveys (Brimeyer and Thomas 
2004). Aerial surveys only sampled a given area once per annum, thereby reducing the likelihood of pseudoreplication. Moose were classified as bulls, yearling bulls, cows, calves ( $<1 \mathrm{yr}$ old), or unclassified adults (Brimeyer and Thomas 2004). Rather than using the number of calves bonded to cows (i.e., "calves at heel") as our recruitment estimate, we calculated the total number of calves per 100 cows from the classification data and used these data to estimate population-level calf recruitment. By doing so, recruitment estimates were not biased by individual or temporal variation in the cow-calf bond (Bonenfant et al. 2005).

\section{Laboratory methods}

Genetic analyses. - To assess diet quality and pregnancy, we determined the individuality and sex of each fecal sample by using nine microsatellite loci to develop multilocus genotypes and a sex marker (Appendix S1: Tables S1, S2). Because genotyping errors are common when working with low-quality DNA, such as that extracted from fecal samples (for review, see Lampa et al. 2013), we used a multiple tubes approach (Taberlet et al. 1996) and genotyped each fragment analysis using two independent observers and program GeneMarker (SoftGenetics). After each round of PCR and fragment analysis, we used program Reliotype (Miller et al. 2002) to estimate the number of additional genotypes needed to identify a reliable genotype for a given fecal sample. This process was iterated until the probability of sample reliability was $>95 \%$ (Miller et al. 2002). We identified individual moose using AlleleMatch in Program R (Galpern et al. 2012, R Core Team 2018). Specifically, we used the probability that two genotypes were indeed unique individuals and not simply siblings with similar genotypes (i.e., probability siblings [Psibs] $<0.05$ ) as a conservative measure of individual identification (Waits et al. 2001). See supplementary materials (Appendix S1) for detailed DNA extraction, PCR, and genotyping protocols.

Fecal nitrogen, fecal progestogens, and pregnancy-specific protein B.-To quantify diet quality for males and females and the pregnancy status of females, we assayed fecal samples of known identity and sex for fecal nitrogen and fecal progestogen. Multiple factors can confound the reliability of fecal nitrogen as an index of diet quality, including sex, lactation status, plant secondary metabolites, and the phenological state of plants during fecal collection (Leslie et al. 2008, Hamel et al. 2009, Monteith et al. 2014b). Although debate exists (e.g., see Leslie and Starkey 1985, 1987, Hobbs 1987; and confounding variables in Appendix S1 for further discussion), fecal nitrogen accurately characterizes forage quality if confounding factors are controlled for statistically (Leslie et al. 2008, Monteith et al. 2014b). We therefore quantified fecal nitrogen in winter for both males and females, but only assessed fecal nitrogen for males during summer because the lactation status of females was unknown. To control for the potential effects of plant phenology on fecal nitrogen concentrations, we regressed fecal nitrogen concentrations against remotely sensed measures of plant phenology (i.e., the Normalized Difference Vegetation Index [NDVI] and days from peak instantaneous rate of green-up [IRG]; see confounding variables in Appendix S1 for further details). By doing so, we ensured that any differences in forage quality observed among populations were because of differences in plant nutritional value rather than simply plant phenology, sex, or lactation status. Fecal nitrogen analyses were conducted by the Washington State Habitat Lab (Washington State University, Pullman, Washington, USA). Six pellets from each fecal sample were chosen at random and oven-dried at $55^{\circ} \mathrm{C}$, ground in a Wiley Mill, passed through a 1.0-mm screen and homogenized. The Dumas method of combustion was used to determine fecal nitrogen using a Truspec $\mathrm{CN}$ analyzer (LECO, St. Joseph, Michigan, USA). We report fecal nitrogen on a percent dry matter basis (Hodgman et al. 1996).

To determine the pregnancy status of females, the Smithsonian Conservation Biology Institute (Front Royal, Virginia, USA) quantified the progestogen concentration of fecal pellets collected during winter. Six pellets from each fecal sample were chosen at random and freeze-dried for 24-48 h in a Labconco Freeze-Dry system at $-50^{\circ} \mathrm{C}$, then thoroughly homogenized into a fine powder. Approximately $0.1 \mathrm{~g}$ was weighed from each sample to control for mass-induced bias in metabolite concentration (Millspaugh and Washburn 2003, Goymann 2012) and a pulse-vortex double extraction with $15 \mathrm{~mL} 70 \%$ ethanol was performed. Ethanol extracts were then stored at $-20^{\circ} \mathrm{C}$ until assayed. Radioimmunoassays were performed on ethanol extracts at previously validated dilutions (Wasser et al. 1991, Monfort et al. 1993) using an in-house 3-H progesterone assay. All hormone extracts were run in duplicate in each assay, and only those with intra-assay variation $(\% \mathrm{CV})$ below $10 \%$ were accepted. Concentrations of fecal hormones are reported as nanogram per gram of dried feces.

To validate a threshold for determining pregnancy from fecal progestogen concentrations, we compared fecal progestogen concentrations of live-captured female moose with serum-based measures of pregnancy-specific protein B $(n=67)$. We also estimated the nutritional condition of each individual using ultrasonography and body-condition scoring. Because live capture, serum collection, determining the presence of pregnancy-specific protein $\mathrm{B}$, and assessment of nutritional condition have been described elsewhere (see Jesmer et al. 2017, 2018), we only briefly summarize those methods here. Adult ( $>1$ yr old), female moose were captured on winter range in February 2013 and 2014 via helicopter net-gunning (Barrett et al. 1982, Krausman et al. 1985). We used ultrasonography to determine the maximum depth of 
subcutaneous rump fat, and used a standardized protocol validated in other species to assign a body-condition score (Stephenson et al. 1998, Cook et al. 2010). Subcutaneous rump fat was used to estimate percent ingestafree body fat for moose with measurable fat. For animals without subcutaneous fat, body-condition scores were used to estimate percent ingesta-free body fat based on the linear relationship between ingesta-free body fat and the body-condition score of moose with measurable rump fat (Cook et al. 2010; K. L. Monteith, unpublished data). We collected fecal samples (10-12 pellets) via rectal palpation, which were immediately frozen at $-20^{\circ} \mathrm{C}$ until assayed for fecal nitrogen and fecal progestogen concentrations. Blood samples $(20 \mathrm{~mL})$ were collected via jugular venipuncture, centrifuged, and serum was pipetted into 5-mL cryovials where it was stored at $-20^{\circ} \mathrm{C}$ until analyzed for the presence of protein-specific protein B. BioTracking (Moscow, Idaho, USA) used the commercially available BioPRYN wild assay to determine pregnancy-specific protein B concentrations. Capture and handling methodologies followed the recommendations of the American Society of Mammalogists (Sikes et al. 2011) and were approved by the Institutional Animal Care and Use Committee at the University of Wyoming (Permit A-3216-01).

Autumn nutritional condition. - Autumn nutritional condition of ungulates determines pregnancy and overwinter survival of both adult females and their juvenile offspring (Cook et al. 2004, Monteith et al. 2014a). We therefore quantified autumn nutritional condition of moose by measuring kidney fat index of hunter-harvested kidneys (Riney 1955, Stephenson et al. 1998). In collaboration with the Wyoming Game and Fish Department, Colorado Parks and Wildlife, and Utah Division of Wildlife Resources, we instructed hunters on how to collect kidneys from harvested moose without disturbing the attached fat. Renal fat forcefully removed from the kidney was indicated by cut marks in the fat or kidney as well as air bubbles within the renal membrane caused by tearing fat away from the membrane. We noted any signs of fat disturbance and excluded all disturbed kidneys from further analysis.

\section{Statistical analyses}

To determine pregnancy, we developed a one-sample fecal pregnancy test using fecal progestogens and pregnancy-specific protein B concentrations collected from live-captured, adult females. We applied a combination of classification and regression tree (CART) analysis (Breiman 1984) and a Monte Carlo resampling approach (Robert et al. 2010) to estimate both a fecal progestogen threshold and confidence intervals for determining pregnancy (for detailed methodology, see modeling approach in Appendix S1).

We used linear regression to assess hypothesized pathways by which density-dependent and density- independent factors influence moose nutrition and juvenile recruitment. Formally, linear regression can be expressed as

$$
y_{i}=\beta_{0}+\sum_{j=1}^{p} \beta_{j} x_{i j}+\varepsilon_{i}
$$

where dependent $\left(y_{i}\right)$ and independent $\left(x_{i}\right)$ observations are assumed to be independent and measured without error. The intercept $\left(\beta_{0}\right)$, slope coefficients $\left(\beta_{j}\right)$, and residual error $\left(\epsilon_{i}\right)$ are estimated parameters, where $\epsilon_{i} \sim \mathrm{N}\left(0, \sigma^{2}\right)$. The assumption of error-free dependent and independent observations is rarely met when using data aggregated across populations, across large spatial scales, or when using remotely sensed data. Aggregate data modeled without explicit incorporation of measurement error, however, still provide valuable insights about the demography of wildlife populations (e.g., Boertje et al. 2007, Brown et al. 2011, Lukacs et al. 2018). Both dependent (i.e., kidney fat index, pregnancy, and calves/100 cows) and independent variables (i.e., diet quality, browse condition, weather variables) were population-level estimates rather than precise measurements. Nevertheless, we did not incorporate measurement error into our regression models for two reasons: (1) sample size for calves/100 cows varied according to population size, such that weighting regression coefficients by their inverse variance would have caused larger populations (in which greater numbers of cows were sampled [e.g., Sublette, Jackson]), to have undue influence on estimation of slope coefficients, and (2) plant phenology, drought, and weather variables were estimated from $>41,500,>3,000$, and $>2,800$ pixels per population per year, respectively, suggesting that our population-level covariates accurately characterized local conditions. Visual inspection of model predictions versus residual plots and the distribution of residuals indicated that our data met the assumption of normally distributed errors.

The slow life history of ungulates results in temporal lags between changing environmental conditions and shifts in vital rates (Gaillard et al. 2000, Monteith et al. 2014a). Because of these lag effects, calf recruitment in any given winter may be influenced by conditions experienced 1-2 yr prior by affecting autumn nutritional condition and pregnancy of adult females (Cook et al. 2004, Taillon et al. 2013). Similarly, conditions from the preceding summer may influence nutritional condition of adult females and their food, thereby influencing lactation, maternal care, and calf recruitment (Gaillard et al. 1997, Hurley et al. 2017, Lukacs et al. 2018). Thus, independent variables at time lags of $0-2 \mathrm{yr}$ were regressed against measures of nutrition and vital rates.

To test the Nutritional Buffer Hypothesis, we evaluated the sensitivity of recruitment in each population to interannual variation in weather and plant phenology (e.g., temperature, precipitation, snowpack, length of spring growing conditions; Fig. 1) by fitting general linear and generalized mixed-effect models to a time series 
of calf recruitment (Fig. 2). To assess non-independence (i.e., temporal autocorrelation) in our time series of calf recruitment data, we fit piecewise regression models and mixed effects models with random slopes and random intercepts while applying autoregressive (AR1) and auto regressive moving average (ARMA) error structures (Muggeo 2008, Pinheiro et al. 2014). We centered and scaled all independent variables to facilitate comparison of effect sizes and to aid in model convergence. Because weather and climate are often correlated, we assessed independence of covariates by calculating pairwise correlations between all independent variables. We excluded any variables with Pearson correlation coefficients $>0.7$ from entering the same model (Dormann et al. 2013). We then used forward stepwise model selection and Akaike's information criterion $\left(\mathrm{AIC}_{\mathrm{C}}\right)$ to identify the most parsimonious parameter set (Burnham and Anderson 2002) while evaluating the variance inflation factor of each covariate to ensure statistical independence among covariates. We quantified goodness of fit via repeated $k$-folds cross validation ( 3 folds, 100 repeats; Kuhn et al. 2015).

To quantify the relationship between climate and calf recruitment from 2001 to 2015, we first used linear discriminant analysis to assess if and how climate across the geographic range of the six populations varied (Legendre and Legendre 2012). To eliminate collinearity among predictor variables and simplify assessment of climate space, we parameterized the ordination with variables from our Akaike information criterion corrected for sample size $\left(\mathrm{AIC}_{\mathrm{c}}\right)$ model-selection procedure. We then used linear regression to evaluate the relationship between the climatic space (i.e., linear discriminate axis 1) occupied by each population and its calf recruitment over a $15-\mathrm{yr}$ period.

\section{RESULTS \\ Genetics (individuality and sex)}

We collected 1,176 samples from fecal transects. The multiple tubes and multiple consensus approach resulted in low genotyping error rates, with allelic dropout and false alleles constituting most of the error (Appendix S1: Table S5). All loci were polymorphic (range $=3-7$; Appendix S1: Table S4) and were not out of HardyWeinberg linkage equilibrium. Full genotypes were established for 709 of $1,176(60 \%)$ samples, representing 218 individuals (sex ratio 58:42; 126 females and 92 males; Appendix S1: Table S5. Number of individuals identified in each study area and season ranged from 1 to 19 (Appendix S1: Table S5).

\section{Forage quantity and quality}

Diet quality (fecal nitrogen) of males in winter was markedly lower and less variable $($ mean $=$ $1.17 \pm 0.03 \mathrm{~g} / 100 \mathrm{~g}$ ) than diet quality of males in summer $\quad($ mean $=2.85 \pm 0.68 \mathrm{~g} / 100 \mathrm{~g} ; \quad$ Appendix S1: Fig. S3). Diet quality was ubiquitously low and nearly identical for males and females (mean $=1.17 \pm 0.02 \mathrm{~g} /$ $100 \mathrm{~g}$ ) in winter (Appendix S1: Fig. S3). Because we sampled diets during the middle of winter and after plant green-up had peaked in summer (see Confounding variables in Appendix S1), fecal nitrogen was not influenced by plant phenology as indexed by NDVI or days from peak IRG (Appendix S1: Fig. S3; all $P>0.05$ ). As assessed through browse condition transects, quantity of preferred forage (i.e., willow) varied among populations (Fig. 4E) and species (S. planifolia, range $=1.44-3.43$ $\mathrm{cm} ; S$. boothii, range $=10.80-15.61 \mathrm{~cm}$ ). Additional measures of browse condition, such as plant height $\left(R^{2}=0.48, P<0.01\right.$ for $S$. boothii) and percent browsed leaders $\left(R^{2}=0.38, \quad P<0.01\right.$ for $S$. boothii, and $R^{2}=0.35, P<0.01$ for $S$. planifolia) were associated with the live-dead index (Appendix S1: Fig. S4), indicating that these less labor-intensive measures accurately depict browse condition.

Kidney fat index.-We collected undisturbed kidneys from 665 moose. After excluding kidneys that lacked age or information about harvest date, the final data set of autumn nutritional condition included 422 kidneys (males, $n=321$; females, $n=101$ ). The nutritional condition (kidney fat index) of males declined as the breeding season progressed (i.e., with Julian day of harvest, $\beta=-0.033[-0.037,-0.028], P<0.001$; Appendix S1: Fig S5A) and as individuals increased in age $(\beta=-0.057[-0.087,-0.025], P<0.001$; Appendix S1: Fig. S5B; see Confounding variables in Appendix S1). Therefore, we used model residuals as a measure of nutritional condition corrected for age and progression of the mating season. For females, kidney fat tended to decline with the progression of the mating season $(\beta=-0.005 \quad[-0.016,0.006]$; Appendix S1: Fig. S5C) and with age $(\beta=-0.005[-0.043,0.056]$; Appendix S1: Fig S5D), but these trends were not statistically significant $(P=0.36$ and $P=0.84$, respectively), so we did not adjust values of the kidney fat index for females.

\section{Fecal progestogens (pregnancy)}

Concentration of fecal progestogens ranged from $237.4-12,703.5 \mathrm{ng} / \mathrm{g}$ in pregnant females, and $216.9-2,943.6 \mathrm{ng} / \mathrm{g}$ in non-pregnant females (pregnancy was determined via the presence of pregnancyspecific protein B in serum samples). Our CART and Monte Carlo resampling approach resulted in a fecal progestogen threshold of 2,291.3 ng/g (95\% confidence interval [1,340.9-3344.9]) for determining pregnancy from fecal samples (Fig. 3A). We therefore considered the pregnancy status of any female with a fecal progestogen concentration within the $95 \%$ confidence interval to be ambiguous and we excluded those samples from further analysis. By excluding samples with 
A

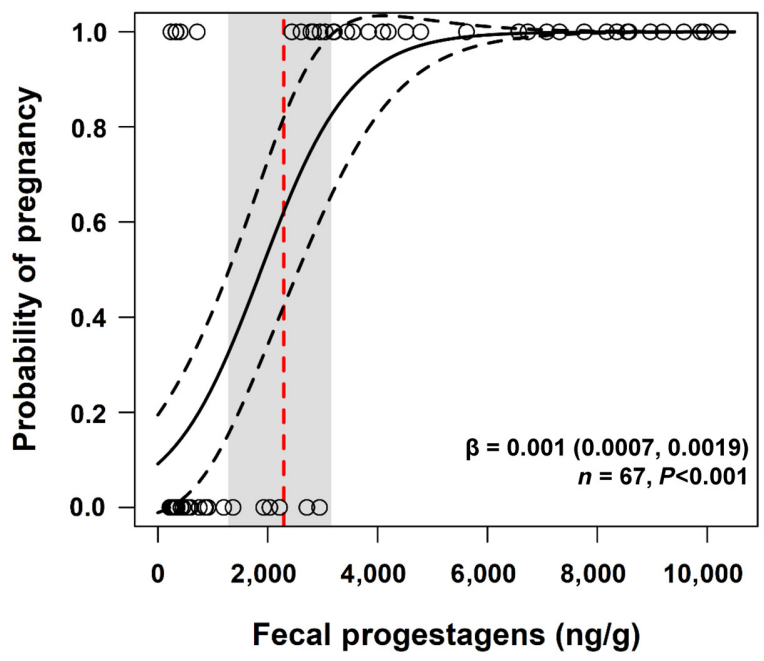

C

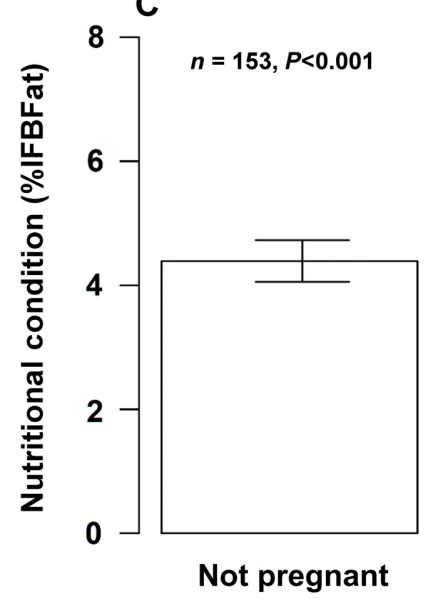

B

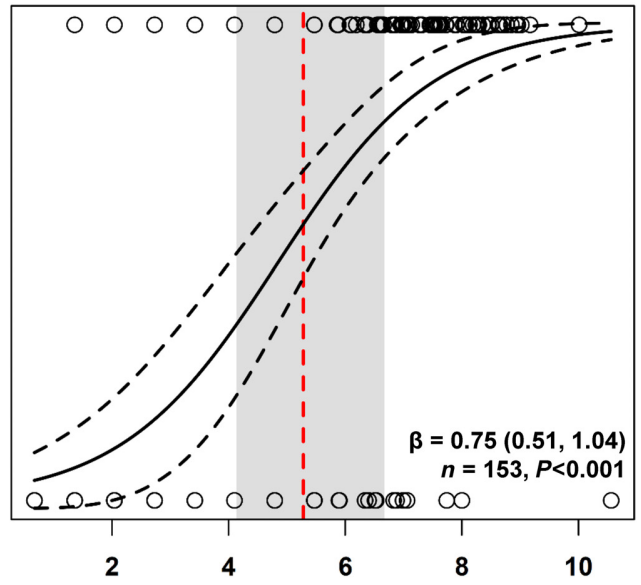

Nutritional condition (\%IFBFat)

D

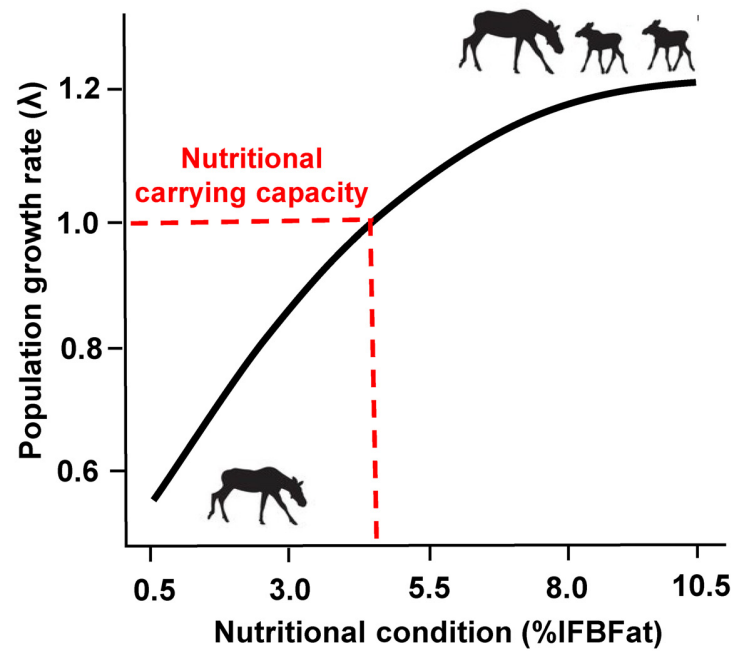

FIG. 3. Relationship between (A) fecal progestogens and pregnancy, (B) nutritional condition of females and pregnancy, and (C) pregnancy status and nutritional condition. (D) Illustration of the hypothesized relationship between nutritional condition and population growth rate. (A) Red dashed line represents the CART-based threshold in fecal progestogens $(2,291.3 \mathrm{ng} / \mathrm{g})$ for determining pregnancy. The gray polygon is the Monte-Carlo-based $95 \%$ confidence interval $(1,340.9-3,344.9 \mathrm{ng} / \mathrm{g})$ for the threshold. By excluding samples with fecal progestogen values falling within the bounds of the gray polygon, $91 \%$ accuracy was achieved because false negatives and false positives were reduced. (B) Red dashed line represents a threshold in nutritional condition (5.3\% ingestafree body fat, confidence interval $4.2 \%$ to $6.4 \%$ ) beyond which probability of pregnancy is extremely high. (D) Red dashed lines indicate the population-level nutritional condition at which population growth is stable (i.e., nutritional carrying capacity, $\lambda=1.0$ ). This heuristic was redrawn from an unpublished empirical study of Sublette moose demography (Oates et al., unpublished manuscript). Note the threshold at which stable population growth is achieved for Sublette moose ( 4.4\% IFBFat) falls within the $95 \%$ confidence interval (4.2-6.4\% IFBFat) for the threshold in nutritional condition that females must reach to become pregnant (panel B). Thus, pregnancy estimates stemming from fecal progestogen may be linked to population growth rate.

ambiguous pregnancy status $(n=16)$, we eliminated false negatives (from $5.6 \%$ to $0 \%$ ) and reduced false positives by $2.4 \%$ (from $18.5 \%$ to $16.1 \%$ ). Altogether, our approach resulted in a single-sample fecal pregnancy test that was $90.2 \%$ accurate (Fig. 3A). Serumbased PSPB accuracy is $95.5 \%$ (Huang et al. 2000), indicating that our method of noninvasive pregnancy assessment was nearly as accurate as serum-based measures.

\section{Measuring resource limitation}

Population-level summer diet quality of males was strongly and positively correlated with recruitment ( $\beta=50.56$ [11.4, 89.68], $P=0.02 ; r=0.79$ [0.32, 1.00], $P<0.01]$; brackets indicate $95 \%$ confidence intervals; Fig. 4A), positively correlated with pregnancy $(\beta=3.10$ $[0.01,6.46], P=0.12 ; r=0.73$ [-0.01, 1.00], $P=0.047$; Fig. 4B), and positively correlated with nutritional 
condition of females in autumn ( $\beta=0.67$ [ $-1.76,3.11]$, $P=0.36 ; r=0.64[-0.07,1.00], P=0.18$; Fig. 4 C). Pregnancy was positively correlated with recruitment ( $\beta=25.8[-25.2,76.7], P=0.28 ; r=0.34[-0.19,1.00]$, $P=0.14$; Fig. 4D). Browse condition was positively correlated with recruitment ( $S$. planifolia, $r=0.93$, $P=0.12$; S. boothii, $r=0.51, P=0.33$; Fig. 4E). Likely owing to small sample sizes ( $n=3-6$ populations), many correlations between population-level means were not statistically significant at $\alpha=0.95$.

Temporal autocorrelation in calf recruitment was weak and was not improved by incorporating autoregressive error structures (i.e., AR1, ARMA; Appendix S1: Fig. S2). Forward stepwise model selection indicated
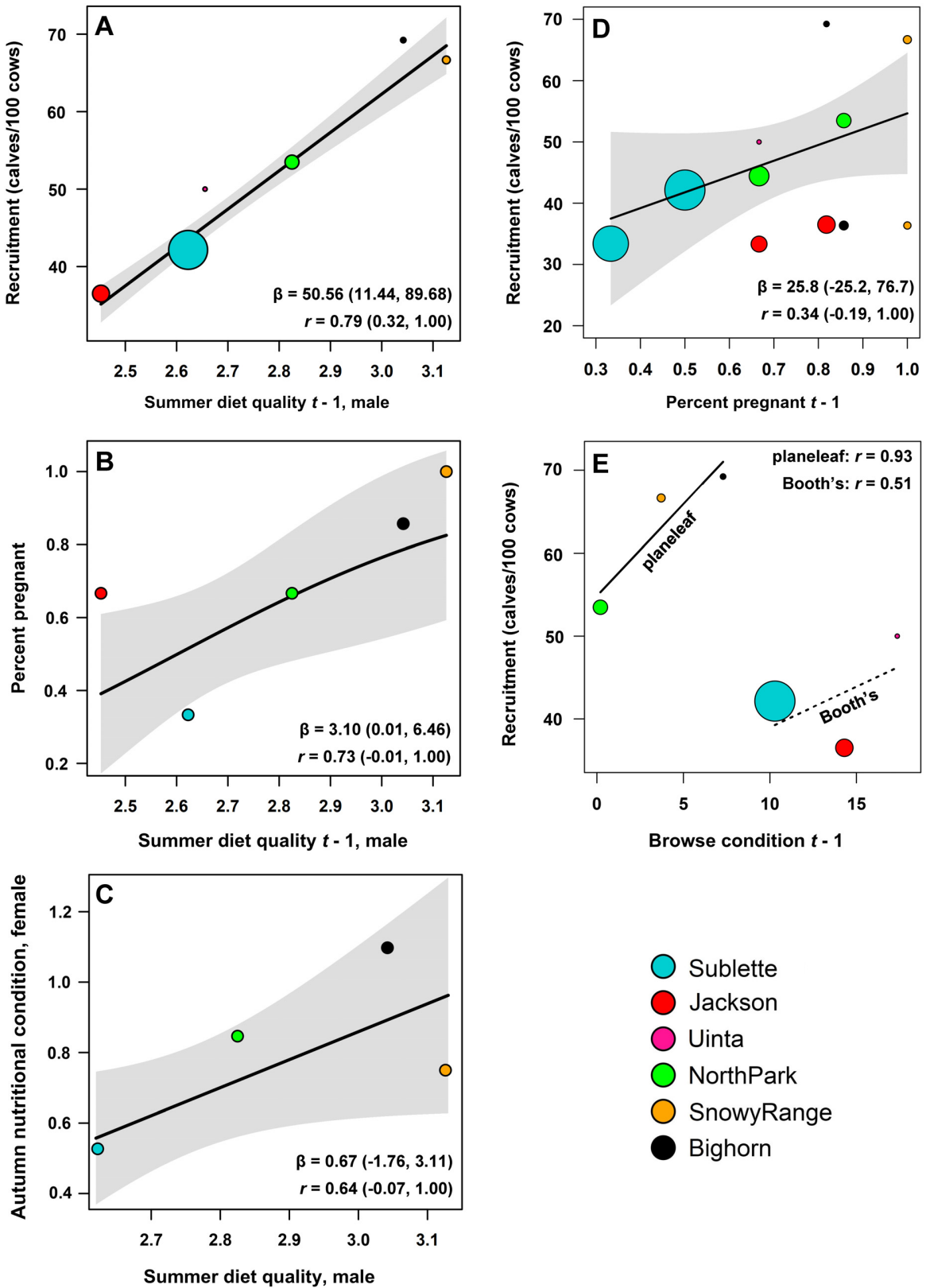

FIG. 4. Relationship between summer diet quality (fecal nitrogen) of males and population-level (A) calf recruitment, (B) pregnancy, and (C) autumn nutritional condition of females. (D) The relationship between pregnancy and calf recruitment, and (E) browse condition (live-dead index) and calf recruitment. t-1 indicates that the independent variable was measured during the calendar preceding the calendar year in which the dependent variable was measured. Size of points in panels A, D, and E reflects number of cow moose classified in a given year. Regression coefficients $(\beta)$, correlation coefficients $(r)$, and $95 \%$ confidence intervals are presented when $n>3$. Solid lines and gray polygons represent predicted relationships and $80 \%$ confidence intervals stemming from regression models. Together, these relationships provide a suite of tools that can be used to measure resource limitation. 
that the relationship between interannual variation in population-level recruitment and weather was not improved by allowing the intercept or slope for each population to vary for any parameter (Appendix S1: Table S6). The top model set (i.e., models within $2 \mathrm{AIC}_{\mathrm{c}}$ units) included five standard linear models and one model that treated population as a random effect (Appendix S1: Table S6). Except for the random intercept term, the random intercept model was identical to the top overall model. A random intercept did not improve model fit (log-likelihood ratio test, $\chi^{2}=0.72$, $P=0.40$ ), so we excluded the random effect model and model averaged the remaining four standard models. Model-averaged parameter estimates indicated a strong, negative effect on calf recruitment of winter severity during the previous year (i.e., SWE; $\beta=-6.09[-8.60$, -3.59 ]; Fig. 5A) when calves were in utero, a strong positive effect of extended spring conditions during the previous year (i.e., spring length; $\beta=3.44$ [0.37, 6.52]; Fig. 5B) and a strong positive effect of PDSI during the growing season of the previous year $(\beta=2.58[0.30$, 4.86]; Fig. 5C, Appendix S1: Table S7) when lactation demands are high. Although forage biomass during the previous year and daily maximum temperature during the growing season two years prior to recruitment were included in the final model, their effects were not statistically significant (confidence intervals overlapped zero) and weak relative to winter severity, spring length, and summer drought (Appendix S1: Table S7). Predictive power of the model was high as demonstrated by $k$-fold cross validation (mean average error $=7.23$ calves $/ 100$ cows) and residual squared error $\left(R^{2}=0.58\right.$; Fig. 5D). Calf recruitment was more sensitive to interannual variation in weather and plant phenology for populations with reduced browse condition, forage quality, and body fat (e.g., Jackson and Sublette) compared to populations
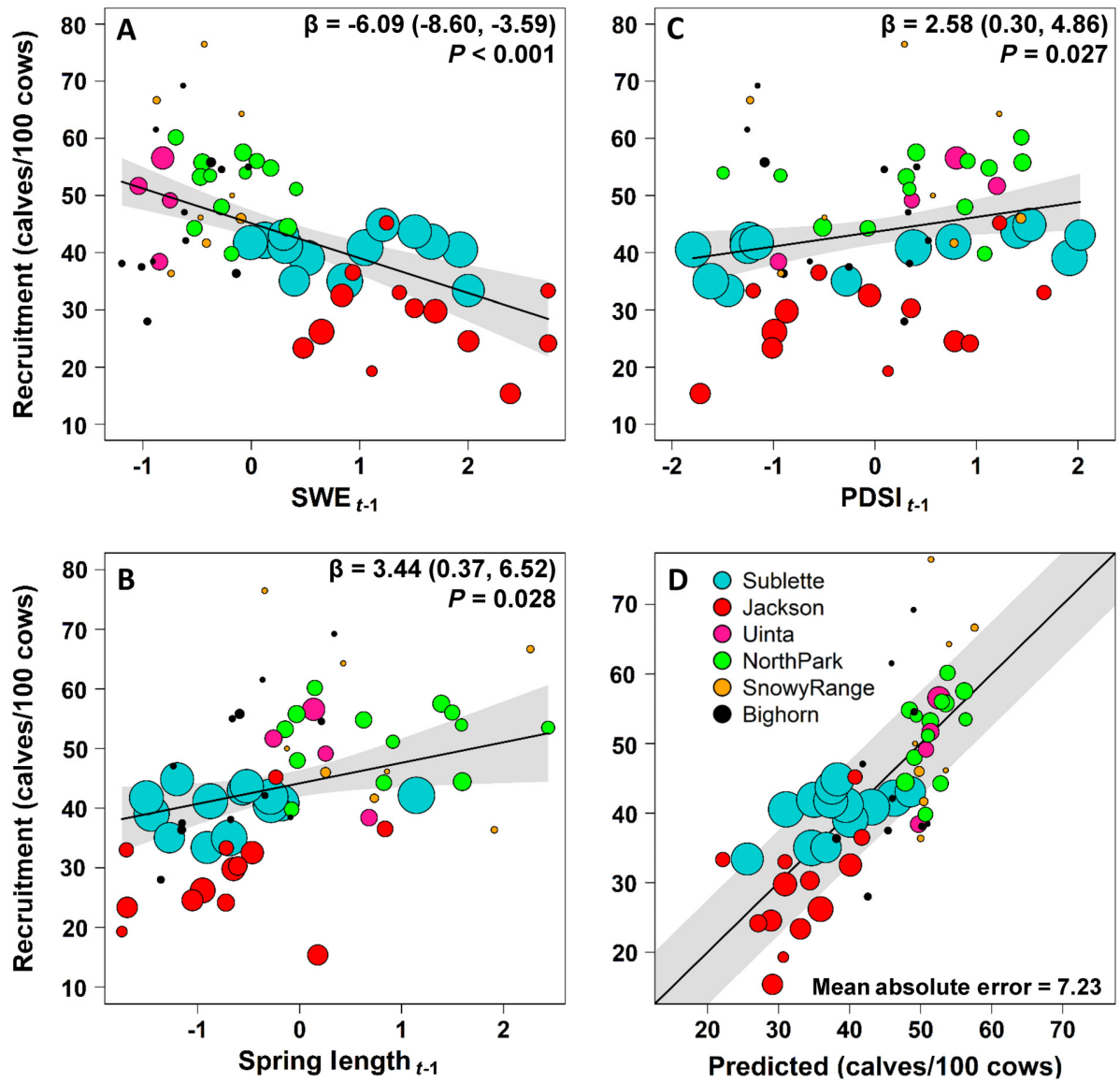

FIG. 5. Relationship between climate, plant phenology, and calf recruitment across six moose populations in the Intermountain West, USA. Partial residual plots illustrate the effect of (A) winter severity (snow water equivalent [SWE]), (B) plant phenology (spring length), and (C) drought (Palmer drought severity index [PDSI]; negative values represent increased drought) on calf recruitment. Size of points reflects number of cow moose classified in a given year. Solid lines and gray polygons represent predicted relationships and their 95\% confidence intervals. Panel D illustrates the predictive power of model averaged equation (Table S7). The solid line is a 1:1 line representing perfect predictability. The gray polygon depicts the mean absolute error $( \pm 7.23$ calves/100 cows) of model predictions according to $k$-folds cross validation. Note that recruitment within some populations varied more strongly with interannual variation in weather than other populations; and average recruitment varied with regional climate (i.e., long-term [ 15 yr] average weather conditions; see Fig. 6). 
with ample resources (e.g., Bighorn and Snowy Range; Figs. 4 and 5), suggesting that these populations lacked the nutritional reserves necessary to buffer demographic performance against the effects of unfavorable weather.

Over the past two decades (2001-2015), calf recruitment was influenced by climatic conditions. The geographic location of populations differed in summer temperature, drought (i.e., PDSI), winter snowpack (i.e., SWE), plant phenology (i.e., spring length), and plant biomass (i.e., iNDVI; Fig. 6A, B). Recruitment was consistently higher in populations that experienced prolonged spring conditions and higher plant biomass $\left(\beta=4.10[3.18,5.03] ; P<0.001, R^{2}=0.95\right.$; Fig. $\left.6 \mathrm{C}\right)$.

\section{DISCUSSION}

Ecologists are increasingly applying the concept of nutritional carrying capacity because they recognize that density-dependent (i.e., resource limitation) and densityindependent factors (i.e., weather) interact to complicate inference about ecological carrying capacity (MacNab 1985, McLeod 1997, Bowyer et al. 2014, Monteith et al. 2014a). By integrating a suite of field, laboratory, and remote-sensing tools with concepts from nutritional ecology and life-history theory (Eberhardt 2002, Parker et al. 2009), we tested the Nutritional Buffer Hypothesis, which serves as a framework for measuring resource limitation and proximity to carrying capacity in ungulates (Fig. 1). We applied this framework to six moose populations to understand the role of density dependence and weather in observed declines of calf recruitment (Fig. 2). Recruitment was associated with noninvasive measures of the previous year's summer diet quality (Fig. 4A), browse condition (Fig. 4E), and pregnancy (Fig. 4D), indicating that resource limitation underpinned declines in calf recruitment across the study region (Fig. 2). Recruitment was more sensitive to interannual variation in weather for populations with lower diet quality, browse condition, and nutritional condition, suggesting that the nutritional reserves of some populations were not sufficient to completely buffer vital rates from the effects of weather (Fig. 5), thereby supporting the Nutritional Buffer Hypothesis (Bowyer et al. 2000, Bowyer et al. 2014). Further, average recruitment from 2001 to 2015 was determined by differences in regional climatic conditions (Fig. 6), suggesting that future shifts in climate are likely to impact nutritional carrying capacity in these populations. These inferences underscore the utility of combining remotely sensed data and measures of browse condition, diet quality, nutritional condition, and pregnancy with the life-history paradigm for estimating degree of nutritional limitation, proximity to nutritional carrying capacity, and potential impacts of climate change.

Understanding how to quantify and detect carrying capacity of ungulate populations has challenged ecologists since the time of Aldo Leopold (1933). This challenge has persisted, in part, because density dependence and density independence do not act independently of each other, thereby obscuring their relative influence on population dynamics (Bowyer et al. 2014). For example, populations near nutritional carrying capacity respond strongly to unfavorable weather conditions and can therefore appear to be regulated independently of density because they lack the nutritional reserves needed to buffer against harsh weather (Coulson et al. 2001, Monteith et al. 2014a; Fig. 1D). In contrast, when populations are held well below nutritional carrying capacity via human harvest or predation, their dynamics tend to be less sensitive to variation in weather because per capita food availability and nutritional reserves are high (Milner et al. 1999; Fig. 1C). Such contrasting effects have led to confusion regarding the relative importance of density-dependent and density-independent factors in determining the population dynamics of long-lived species with slow life histories (Bowyer et al. 2014). By evaluating both resource limitation and weather across six populations with contrasting demography (Fig. 2), we were able to test the Nutritional Buffer Hypothesis and hence disentangle the influence of density-dependent and density-independent processes. Where forage quantity (i.e., low browsing intensity indicative of high per capita browse availability; Fig. 4E) and forage quality (Fig. 4A-C) were high (e.g., Bighorn and Snowy Range), variation in calf recruitment was not explained by interannual variation in weather (Fig. 5), indicating these populations were below carrying capacity and buffered from unfavorable weather conditions. Such lack of model fit, however, may stem from a range of factors, including uncertainty in recruitment estimates and unmeasured drivers of forage quantity or quality. In contrast, where browse condition and forage quality were low (Fig. 4; e.g., Jackson and Sublette), variation in calf recruitment largely was explained by interannual variation in weather (Fig. 5). In summary, by using a framework derived from life-history theory and nutritional ecology to test the Nutritional Buffer Hypothesis (Fig. 1), we demonstrated that metrics of resource limitation and weather in tandem can be useful to understand proximity to nutritional carrying capacity. We hope this framework will serve as a guide for future studies of ungulate demography and management.

Climate warming and drying threaten animal populations around the globe (Parmesan and Yohe 2003, Parmesan 2006). Relative to smaller-bodied species, large mammals $(>3 \mathrm{~kg})$ are highly sensitive to environmental change, because of slow population growth rates and their diminished ability to use microhabitats as thermal refugia (Cardillo et al. 2005, McCain and King 2014). Compared with those near the center of their geographic range, populations near range limits are more likely to experience weather and patterns of plant phenology that challenge their physiological limits (Portner and Farrell 2008). Indeed, southern moose populations appear to be physiologically stressed and have low recruitment relative to populations from higher latitudes (Ruprecht et al. 2016). Theoretically, however, shifts in 

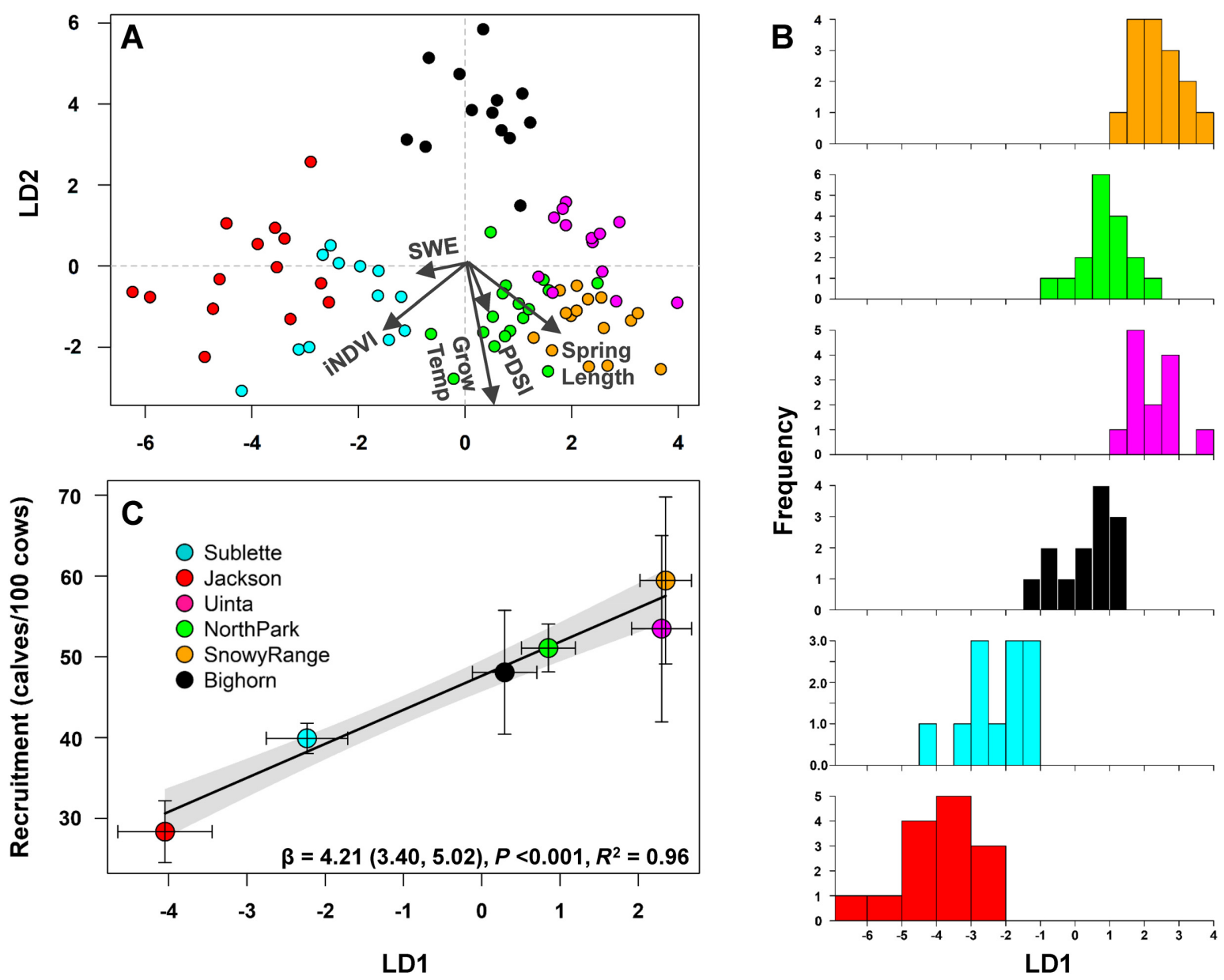

FIG. 6. (A) Relationship between multidimensional climate space (i.e., linear discriminate factors 1 and 2 [LD1 and LD2, respectively]) and geographic location of six moose populations across the Intermountain West, USA (see Fig. 2). LD1 explained $85 \%$ of among-population climate variation, whereas LD2 explained $13 \%$ of among-population climate variation. Variable loadings are depicted by arrows in panel A: winter severity (snow water equivalent [SWE]), plant phenology (spring length), and drought (Palmer drought severity index [PDSI]). Arrow size represents the effect size of each variable. (B) Histograms further illustrate among-population variation in climate from 2001 to 2015. Histograms are ordered from high to low calf recruitment. (C) Relationship between mean LD1 values and mean calf recruitment from 2001 to 2015 . Solid lines and gray polygons represent the predicted relationship ( $\beta$ ) and 95\% confidence interval for the generalized linear regression model. Error bars illustrate $95 \%$ confidence intervals for population means.

weather and plant phenology should only reduce recruitment when populations are near nutritional carrying capacity or when weather and phenological conditions are extreme (Fig. 1). Our mechanistic framework highlights that spatiotemporal variation in weather influenced calf recruitment through its effect on the forage base, which influenced the nutritional condition of females and determined recruitment (Figs. 1, 3-6). Moreover, weather accounted for $52 \%$ of interannual variation in recruitment, and regional variation in climate explained $95 \%$ of variation in average populationlevel recruitment over the past $15 \mathrm{yr}$ (Figs. 5, 6). Thus, and in the absence of strong top-down forcing, declines in recruitment along the southern range limits of moose likely stem from a reduction in nutritional carrying capacity caused by a changing climate.
Key to advancing understanding of the interacting influence of density-dependent and density-independent factors is the capacity to quantify animal nutrition, habitat condition, weather and climate, and demographic parameters. Our study validated and improved upon several preexisting methodologies and approaches, and thus bolsters the ability of practitioners to quantify parameters to evaluate resource limitation and proximity to nutritional carrying capacity. For example, pregnancy is underpinned by nutritional condition (Parker et al. 2009) and is helpful in understanding the demography of ungulates because juvenile recruitment strongly influences population growth (Gaillard et al. 2000, Cook et al. 2004, Raithel et al. 2007). Although statistical power $(n=6)$ hindered our ability to find significant relationships between vital rates, we were able to link 
pregnancy rates derived from fecal progestogens with recruitment (Fig. 4D) by establishing a single-sample test and threshold for pregnancy (Fig. 3A). Our threshold aligns with others developed for moose and elk beginning in approximately February (Monfort et al. 1993, Garrott et al. 1998, Murray et al. 2006), but was well below the threshold developed for moose in the month of May (Murray et al. 2012). To use our threshold, we suggest collecting fecal samples in mid-winter (e.g., February) because circulating levels of progesterone, and thus fecal progestogens, increase throughout pregnancy (Monfort et al. 1993). The relationship between nutritional condition and pregnancy observed here (Fig. 3B) suggests that estimates of population-level pregnancy provide a coarse measure of population-level nutritional condition (Fig. 3C). Because nutritional condition underlies pregnancy and recruitment, fecal-based assessments of pregnancy may be directly linked to population growth rate as has been previously reported for mule deer (Odocoileus hemionus; Monteith et al. 2014a) and moose (Oates et al., unpublished manuscript; Fig. 3 D). Thus, fecal-based estimates of pregnancy represent a promising tool for estimating population-level nutritional condition, population growth rate, and proximity to nutritional carrying capacity.

In addition to developing linkages between population-level pregnancy rates, nutritional condition, and nutritional carrying capacity, we also validated the use of browse surveys, fecal nitrogen, and the kidney-fat index as measures of resource limitation. Although the influence of browsing on forage quality, nutrition, and demography of moose in Alaska has received much attention (Bryant et al. 1983, Boertje et al. 2007, McArt et al. 2009, Seaton et al. 2011, Paragi et al. 2015), these relationships have yet to be evaluated for southern moose populations that reside in markedly different habitats and climates. Forage quality and browse condition were strongly correlated with pregnancy and calf recruitment (Fig. 4), indicating that, like in many Alaskan moose populations, food limitation likely was responsible for the observed patterns of reduced recruitment in southern moose populations. Although the quantity and quality (i.e., amount digestible energy and protein) of forage likely reflects the degree of density-dependence experienced by a population, density-independent factors (i.e., weather) interact with densitydependent factors to influence vital rates. For this reason, quantifying nutritional reserves (e.g., body fat) is an ideal approach to measuring resource limitation and proximity to nutritional carrying capacity because nutritional condition integrates density-dependent and density-independent factors (Parker et al. 2009, Monteith et al. 2014a).

The long-established kidney-fat index (Riney 1955) is known to quantify the nutritional condition of moose (Stephenson et al. 1998), yet citizen scientists (e.g., big game hunters) are rarely used to collect kidneys because it is assumed that biologists trained in kidney extraction are needed to ensure data quality (Anderson et al. 1990). We provided two lines of evidence suggesting that hunter-harvested kidneys can offer accurate measures of body fat and thus nutritional condition. First, and in accordance with the annual energetic cycle of male moose, values of the kidney-fat index declined predictably as the breeding season progressed (Fig. S5A) and with age (Appendix S1: Fig. S5B; Schwartz et al. 1984). Although declines in female kidney fat throughout the breeding season were not statistically significant (Appendix S1: Fig. S5C), trends in kidney fat of females declined with both progression of the breeding season and with age as expected according to annual energetic cycle of female moose (Schwartz et al. 1984, Parker et al. 2009, Appendix S1: Fig. S5D). Second, population-level nutritional condition as indexed by female kidney fat was correlated positively with summer diet quality of males (Fig. 3C). Together, these results indicate that measures of kidney fat derived from hunter-harvested animals, including males, provide a viable means of indexing population-level nutritional condition. Thus, measures of browse condition, fecal nitrogen, and kidney fat offer simple, cost effective monitoring tools that can be readily implemented to estimate resource limitation and hence proximity to nutritional carrying capacity.

A major goal in population ecology is to understand how resource limitation underlies shifts in demography. Concurrently, wildlife managers often attempt to maximize sustainable yield and prevent density-dependent declines by setting harvest limits that prevent populations of ungulates from exceeding carrying capacity (Boertje et al. 2009, Connelly et al. 2012). By integrating life-history theory, nutritional ecology, and a suite of field, laboratory, and remote-sensing tools, we offer a framework wherein measures of browse (or grazing) conditions, diet quality, nutritional condition, pregnancy, weather and climate can be combined to provide a low-cost means for monitoring resource limitation and thus, proximity to nutritional carrying capacity, as well as the potential impacts of future climate change. We hope the approach that we have outlined and tested enhances the ability of ecologists to understand when and where populations are near nutritional carrying capacity to facilitate data-driven decisions in wildlife management.

\section{ACKNOWLedgments}

We thank Aimee Hurt, Ngaio Richards, Wicket, and Orbee from Working Dogs for Conservation for their assistance with locating moose feces, B. Davitt and the staff of the Washington State Wildlife Habitat Lab for estimating fecal N and NDF, J. Brown and the Center for Species Survival at the Smithsonian Conservation Biology Institute for quantifying fecal progestogen concentrations, J. Branen and the staff of BioTracking LLC for conducting the BioPryn Wild ELISA assays, the Matson Laboratory for analyzing tooth age, Jerod Merkle for assistance with quantifying plant phenology from NDVI data, and Melanie Murphy for providing laboratory space and guidance in 
fecal DNA analysis. This work was supported by grants from the Wyoming Game and Fish Department, Wyoming Wildlife -The Foundation, Colorado Parks and Wildlife, USDA National Forest Service, Bridger-Teton National Forest, the University of Wyoming-National Park Service Research Center, and the Alces Society. Any mention of trade, product, or firm names is for descriptive purposes only and does not imply endorsement by the U.S. Government.

\section{Literature Cited}

Abatzoglou, J. T., R. Barbero, J. W. Wolf, and Z. Holden. 2014. Tracking interannual streamflow variability with drought indices in the Pacific Northwest, US. Journal of Hydrometeorology 15:1900-1912.

Anderson, A., D. C. Bowden, and E. Medin. 1990. Indexing the annual fat cycle in a mule deer population. Journal of Wildlife Management 54:550-556.

Anderson, T. M., M. E. Ritchie, E. Mayemba, S. Eby, J. B. Grace, and S. J. McNaughton. 2007. Forage nutritive quality in the Serengeti ecosystem: the roles of fire and herbivory. American Naturalist 170:343-357.

Augustine, D. J., and S. J. McNaughton. 1998. Ungulate effects on the functional species composition of plant communities: herbivore selectivity and plant tolerance. Journal of Wildlife Management 62:1165-1183.

Baigas, P. E. 2008. Winter habitat selection, winter diet, and seasonal distribution mapping of Shiras moose (Alces alces shirasi) in southeastern Wyoming. University of Wyoming, Laramie, Wyoming, USA.

Baigas, P. E., R. A. Olson, R. M. Nielson, S. N. Miller, and F. G. Lindzey. 2010. Modeling seasonal distribution and spatial range capacity of moose in southeastern Wyoming. Alces 46:89-112.

Barrett, M. W., J. W. Nolan, and L. D. Roy. 1982. Evaluation of a hand held net gun to capture large mammals. Wildlife Society Bulletin 10:108-114.

Becker, S. A. 2008. Habitat selection, condition, and survival of Shiras moose in northwest Wyoming. University of Wyoming, Laramie, Wyoming, USA.

Bischof, R., L. E. Loe, E. L. Meisingset, B. Zimmermann, B. Van Moorter, and A. Mysterud. 2012. A migratory northern ungulate in the pursuit of spring: jumping or surfing the green wave? American Naturalist 180:407-424.

Boertje, R. D., M. A. Keech, D. D. Young, K. A. Kellie, and C. T. Seaton. 2009. Managing for elevated yield of moose in interior Alaska. Journal of Wildlife Management 73:314-327.

Boertje, R. D., K. A. Kellie, C. T. Seaton, M. A. Keech, D. D. Young, B. W. Dale, L. G. Adams, and A. R. Aderman. 2007. Ranking Alaska moose nutrition: signals to begin liberal antlerless harvests. Journal of Wildlife Management 71:1494-1506.

Bonenfant, C., et al. 2009. Empirical evidence of density-dependence in populations of large herbivores. Advances in Ecological Research 41:313-357.

Bonenfant, C., J. M. Gaillard, F. Klein, and J.-L. Hamann. 2005. Can we use the young: female ratio to infer ungulate population dynamics? An empirical test using red deer Cervus elaphus as a model. Journal of Applied Ecology 42:361-370.

Borowik, T., N. Pettorelli, L. Sönnichsen, and B. Jędrzejewska. 2013. Normalized difference vegetation index (NDVI) as a predictor of forage availability for ungulates in forest and field habitats. European Journal of Wildlife Research 59:675-682.

Bowyer, R. T., V. C. Bleich, K. M. Stewart, J. C. Whiting, and K. L. Monteith. 2014. Density dependence in ungulates: a review of causes, and concepts with some clarifications. California Fish and Game 100:550-572.

Bowyer, R. T., D. M. Leslie, and J. L. Rachlow. 2000. Dall's and Stone's sheep. Pages 491-516 in P. R. Krausman and S. Demarais, editor. Ecology and managament of large mammals in North America. Prentice Hall, Columbus, Ohio, USA.

Breiman, L. 1984. Classification and regression trees. Chapman \& Hall, London, UK.

Breiman, L. 2001. Random forests. Machine Learning 45:5-32.

Brimeyer, D. G., and T. P. Thomas. 2004. History of moose management in Wyoming and recent trends in Jackson Hole. Alces 40:133-143.

Brown, G. S. 2011. Patterns and causes of demographic variation in a harvested moose population: evidence for the effects of climate and density-dependent drivers. Journal of Animal Ecology 80:1288-1298.

Bryant, J. P., F. S. III Chapin, and D. R. Klein. 1983. Carbon/ nutrient balance of boreal plants in relation to vertebrate herbivory. Oikos 40:357-368.

Bryant, J. P., P. B. Reichardt, and T. Clausen. 1992. Chemically mediated interactions between woody plants and browsing mammals. Journal of Range Management 45:18-24.

Burnham, K. P., and D. R. Anderson 2002. Model selection and multimodel inference. Second edition. Springer-Verlag, New York, New York, USA.

Cardillo, M., G. M. Mace, K. E. Jones, J. Bielby, O. R. P. Bininda-Emonds, W. Sechrest, C. D. L. Orme, and A. Purvis. 2005. Multiple causes of high extinction risk in large mammal species. Science 309:1239-1241.

Connelly, J. W., J. H. Gammonley, and T. W. Keegan. 2012. Harvest management. Pages 202-231 in N. J. Silvy, editor. The wildlife techniques manual. Johns Hopkins University Press, Baltimore, Maryland, USA.

Cook, J. G., B. K. Johnson, R. C. Cook, R. A. Riggs, T. Delcurto, L. D. Bryant, and L. L. Irwin. 2004. Effects of summer-autumn nutrition and parturition date on reproduction and survival of elk. Wildlife Monographs 155:1-61.

Cook, R. C., et al. 2010. Revisions of rump fat and body scoring indices for deer, elk, and moose. Journal of Wildlife Management 74:880-896.

Coulson, T., E. A. Catchpole, S. D. Albon, B. J. T. Morgan, J. M. Pemberton, T. H. Clutton-Brock, M. J. Crawley, and B. T. Grenfell. 2001. Age, sex, density, winter weather, and population crashes in Soay sheep. Science 292:1528-1531.

Craine, J. M., J. B. Nippert, A. J. Elmore, A. M. Skibbe, S. L. Hutchinson, and N. A. Brunsell. 2012. Timing of climate variability and grassland productivity. Proceedings of the National Academy of Sciences USA 109:3401-3405.

Dahlgren, D. K., R. D. Elmore, D. A. Smith, A. Hurt, E. Arnett, and J. Connelly. 2012. Use of dogs in wildlife research and management. Pages 140-153 in N. J. Silvy, editor. Wildlife techniques manual. John Hopkins University Press, Baltimore, Maryland, USA.

DeCesare, N. J., T. D. Smucker, R. A. Garrott, and J. A. Gude. 2014. Moose status and management in Montana. Alces: A Journal Devoted to the Biology and Management of Moose 50:35-51.

Dormann, C. F., et al. 2013. Collinearity: a review of methods to deal with it and a simulation study evaluating their performance. Ecography 36:27-46.

Eberhardt, L. L. 2002. A paradigm for population analysis of long-lived vertebrates. Ecology 83:2841-2854.

Evans, J. S., M. A. Murphy, Z. A. Holden, and S. A. Cushman 2011. Modeling species distribution and change using Random Forest. Pages 139-159 in C. A. Drew, Y. F. Wiersma, and F. Huettmann, editors. Predictive species and habitat 
modeling in landscape ecology: concepts and applications. Springer, New York, New York, USA.

Gaillard, J.-M., J.-M. Boutin, D. Delorme, G. Van Laere, P. Duncan, and J.-D. Lebreton. 1997. Early survival in roe deer: causes and consequences of cohort variation in two contrasted populations. Oecologia 112:502-513.

Gaillard, J. M., M. Festa-Bianchet, and N. G. Yoccoz. 1998. Population dynamics of large herbivores: variable recruitment with constant adult survival. Trends in Ecology \& Evolution 13:58-63.

Gaillard, J. M., M. Festa-Bianchet, N. G. Yoccoz, A. Loison, and C. Toigo. 2000. Temporal variation in fitness components and population dynamics of large herbivores. Annual Review of Ecology and Systematics 31:367-393.

Galpern P., M. Manseau, P. Hettinga, and K. Smith. 2012. Allelematch: an $\mathrm{R}$ package for identifying unique multilocus genotypes where genotyping error and missing data may be present. Molecular Ecology Resources 12(4):771-778. https:// doi.org/10.1111/j.1755-0998.2012.03137.x.

Garrott, R. A., S. L. Monfort, P. J. White, K. L. Mashburn, and J. G. Cook. 1998. One-sample pregnancy diagnosis in elk using fecal steroid metabolites. Journal of Wildlife Diseases $34: 126-131$.

Goymann W. 2012. On the use of non-invasive hormone research in uncontrolled, natural environments: the problem with sex, diet, metabolic rate and the individual. Methods in Ecology and Evolution 3(4):757-765. https://doi.org/10.1111/ j.2041-210x.2012.00203.x.

Hamel S., M. Garel, M. Festa-Bianchet, J-M. Gaillard, and S. D. Côté. 2009. Spring Normalized Difference Vegetation Index (NDVI) predicts annual variation in timing of peak faecal crude protein in mountain ungulates. Journal of Applied Ecology 46(3):582-589. https://doi.org/10.1111/j. 1365-2664.2009.01643.x.

Harrison, X. A., J. D. Blount, R. Inger, D. R. Norris, and S. Bearhop. 2011. Carry-over effects as drivers of fitness differences in animals. Journal of Animal Ecology 80:4-18.

Hebblewhite, M., E. Merrill, and G. McDermid. 2008. A multiscale test of the forage maturation hypothesis in a partially migratory ungulate population. Ecological Monographs $78: 141-166$

Henningsen, J. C., A. L. Williams, C. M. Tate, S. A. Kilpatrick, and D. W. Walter. 2012. Distribution and prevalence of Elaeophora schneideri in moose in Wyoming. Alces 48:35-44.

Hobbs, N. T. 1987. Fecal indexes to dietary quality-a critique. Journal of Wildlife Management 51:317-320.

Hodgman, T. P., B. B. Davitt, and J. R. Nelson. 1996. Monitoring mule deer diet quality and intake with fecal indices. Journal of Range Management 49:215-222.

Homer, C., J. Dewitz, L. Yang, S. Jin, P. Danielson, G. Xian, J. Coulston, N. Herold, J. Wickham, and K. Megown. 2015. Completion of the 2011 National Land Cover Database for the conterminous United States-representing a decade of land cover change information. Photogrammetric Engineering \& Remote Sensing 81:345-354.

Huang, F., D. C. Cockrell, T. R. Stephenson, J. H. Noyes, and R. G. Sasser. 2000. A serum pregnancy test with a specific radioimmunoassay for moose and elk pregnancy-specific protein B. Journal of Wildlife Management 64:492.

Hurley, M. A., M. Hebblewhite, P. M. Lukacs, J. J. Nowak, J.M. Gaillard, and C. Bonenfant. 2017. Regional-scale models for predicting overwinter survival of juvenile ungulates. Journal of Wildlife Management 81:364-378.

Jesmer, B., M. Kauffman, A. Courtemanch, S. Kilpatrick, T. Thomas, J. Yost, K. Monteith, and J. Goheen. 2020. Data from: Life-history theory provides a framework for detecting resource limitation: a test of the Nutritional Buffer
Hypothesis. Dryad, data set. https://doi.org/10.5061/dryad. z8w9ghx9s

Jesmer B. R., M. J. Kauffman, M. A. Murphy, and J. R. Goheen. 2020. A test of the Niche Variation Hypothesis in a ruminant herbivore. Journal of Animal Ecology 89(12):2825 -2839. https://doi.org/10.1111/1365-2656.13351.

Jesmer, B. R., et al. 2018. Is ungulate migration culturally transmitted? Evidence of social learning from translocated animals. Science 361:1023-1025.

Jesmer, B. R., J. R. Goheen, K. L. Monteith, and M. J. Kauffman. 2017. State-dependent behavior alters endocrine-energy relationship: implications for conservation and management. Ecological Applications 27:2303-2312.

Keech, M. A., R. T. Bowyer, J. M. Ver Hoef, R. D. Boertje, B. W. Dale, and T. R. Stephenson. 2000. Life-history consequences of maternal condition in Alaskan moose. Journal of Wildlife Management 64:450-462.

Keigley, R. B., and C. W. Fager. 2006. Habitat-based adaptive management at Mount Haggin Wildlife Mangement Area. Alces 42:49-54.

Kincaid, T., A. Olsen, D. Stevens, C. Platt, D. White, and R. Remington. 2012. spsurvey: Spatial survey design and analysis. $\mathrm{R}$ package version 2.6. https://cran.r-project.org/web/pac kages/spsurvey/index.html

Krausman, P. R., J. J. Hervert, and L. L. Ordway. 1985. Capturing deer and mountain sheep with a net-gun. Wildlife Society Bulletin 13:71-73.

Kuhn, M., J. Wing, and S. Weston. 2015. Package 'caret'. Classification and regression training. https://cran.r-project.org/ web/packages/caret/index.html

Lampa, S., K. Henle, R. Klenke, M. Hoehn, and B. Gruber. 2013. How to overcome genotyping errors in non-invasive genetic mark-recapture population size estimation-A review of available methods illustrated by a case study. Journal of Wildlife Management 77:1490-1511.

Legendre, P., and L. F. Legendre. 2012. Numerical ecology. Elsevier, Amsterdam, the Netherlands.

Lenarz, M. S., J. Fieberg, M. W. Schrage, and A. J. Edwards. 2010. Living on the edge: viability of moose in Northeastern Minnesota. Journal of Wildlife Management 74:1013-1023.

Lenarz, M. S., M. E. Nelson, M. W. Schrage, and A. J. Edwards. 2009. Temperature mediated moose survival in northeastern Minnesota. Journal of Wildlife Management 73:503-510.

Leopold, A. 1933. Game management. C. Scribner's Sons, New York, New York, USA.

Leslie, D. M., R. T. Bowyer, and J. A. Jenks. 2008. Facts from feces: nitrogen still measures up as a nutritional index for mammalian herbivores. Journal of Wildlife Management 72:1420-1433.

Leslie, D., and E. Starkey. 1985. Fecal indexes to dietary quality of cervids in old-growth forests. Journal of Wildlife Management 49:142-146.

Leslie, D., and E. Starkey. 1987. Fecal indexes to dietary quality - a reply. Journal of Wildlife Management 51:321-325.

Liaw, A., and M. Wiener. 2002. Classification and regression by random forest. $\mathrm{R}$ News 2(3):18-22.

Lukacs, P. M., et al. 2018. Factors influencing elk recruitment across ecotypes in the Western United States. Journal of Wildlife Management 82:698-710.

MacNab, J. 1985. Carrying capacity and related slippery shibboleths. Wildlife Society Bulletin (1973-2006) 13:403-410.

Mautz, W. W., J. L. Schmidt, and D. L. Gilbert. 1978. Nutrition and carrying capacity. Pages 321-348 in J. L. Schmidt and D. L. Gilbert editors. Big game of North America: ecology and management. Stack-pole, Harrisburg, Pennsylvania, USA.

McArt, S. H., D. E. Spalinger, W. B. Collins, E. R. Schoen, T. Stevenson, and M. Bucho. 2009. Summer dietary nitrogen 
availability as a potential bottom-up constraint on moose in south-central Alaska. Ecology 90:1400-1411.

McCain, C. M., and S. R. B. King. 2014. Body size and activity times mediate mammalian responses to climate change. Global Change Biology 20:1760-1769.

McCullough, D. R. 1979. The George Reserve deer herd: population ecology of a K-selected species. University of Michigan Press, Ann Arbor, Michigan, USA.

McCullough, D. R. 1999. Density dependence and life-history strategies of ungulates. Journal of Mammalogy 80:1130-1146.

McLeod, S. R. 1997. Is the concept of carrying capacity useful in variable environments? Oikos 79:529-542.

Miller, C. R., P. Joyce, and L. P. Waits. 2002. Assessing allelic dropout and genotype reliability using maximum likelihood. Genetics 160(1):357-366.

Millspaugh J. J., and Washburn B. E. 2003. Within-sample variation of fecal glucocorticoid measurements. General and Comparative Endocrinology 132(1):21-26. https://doi.org/10. 1016/s0016-6480(03)00061-3.

Milner, J. M., D. A. Elston, and S. D. Albon. 1999. Estimating the contributions of population density and climatic fluctuations to interannual variation in survival of Soay sheep. Journal of Animal Ecology 68:1235-1247.

Monfort, S. L., C. C. Schwartz, and S. K. Wasser. 1993. Monitoring reproduction in captive moose using urinary and fecal steroid metabolites. Journal of Wildlife Management 57:400.

Monteith, K. L., V. C. Bleich, T. R. Stephenson, B. M. Pierce, M. M. Conner, J. G. Kie, and R. T. Bowyer. 2014a. Life-history characteristics of mule deer: Effects of nutrition in a variable environment. Wildlife Monographs 186:1-62.

Monteith, K., R. Klaver, K. Hersey, A. A. Holland, T. Thomas, and M. Kauffman. 2015. Effects of climate and plant phenology on recruitment of moose at the southern extent of their range. Oecologia 178:1137-1148.

Monteith, K. B., K. L. Monteith, R. T. Bowyer, D. M. Jr Leslie, and J. A. Jenks. 2014b. Reproductive effects on fecal nitrogen as an index of diet quality: an experimental assessment. Journal of Mammalogy 95:301-310.

Muggeo, V. M. 2008. Segmented: an R package to fit regression models with broken-line relationships. R News 8:20-25.

Murray, D. L., E. W. Cox, W. B. Ballard, H. A. Whitlaw, M. S. Lenarz, T. W. Custer, T. Barnett, and T. K. Fuller. 2006. Pathogens, nutritional deficiency, and climate influences on a declining moose population. Wildlife Monographs (166): 1-29.

Murray, D. L., et al. 2012. Assessment of the status and viability of a population of moose (Alces alces) at its southern range limit in Ontario. Canadian Journal of Zoology 90:422-434.

Musante, A. R., P. J. Pekins, and D. L. Scarpitti. 2010. Characteristics and dynamics of a regional moose Alces alces population in the northeastern United States. Wildlife Biology 16:185-204.

Paragi, T. F., C. T. Seaton, K. A. Kellie, R. D. Boertje, K. Kielland, D. D. Jr Young, M. A. Keech, and S. D. DuBois. 2015. Browse removal, plant condition, and twinning rates before and after short-term changes in moose density. Alces: A Journal Devoted to the Biology and Management of Moose 51:1-21.

Parker, K. L., P. S. Barboza, and M. P. Gillingham. 2009. Nutrition integrates environmental responses of ungulates. Functional Ecology 23:57-69.

Parker, K. L., M. P. Gillingham, T. A. Hanley, and C. T. Robbins. 1999. Energy and protein balance of free-ranging blacktailed deer in a natural forest environment. Wildlife Monographs (143):3-48.
Parmesan, C. 2006. Ecological and evolutionary responses to recent climate change. Annual Review of Ecology, Evolution, and Systematics 37:637-669.

Parmesan, C., and G. Yohe. 2003. A globally coherent fingerprint of climate change impacts across natural systems. Nature 421:37.

Pettorelli, N., F. Pelletier, A. V. Hardenberg, M. Festa-Bianchet, and S. D. Côté. 2007. Early onset of vegetation growth vs. rapid green-up: impacts on juvenile mountain ungulates. Ecology 88:381-390.

Pettorelli, N., J. O. Vik, A. Mysterud, J. M. Gaillard, C. J. Tucker, and N. C. Stenseth. 2005a. Using the satellite-derived NDVI to assess ecological responses to environmental change. Trends in Ecology \& Evolution 20:503-510.

Pettorelli, N., R. B. Weladji, O. Holand, A. Mysterud, H. Breie, and N. C. Stenseth. 2005b. The relative role of winter and spring conditions: linking climate and landscape-scale plant phenology to alpine reindeer body mass. Biology Letters 1:24-26.

Pinheiro, J., D. Bates, S. DebRoy, D. Sarkar, and R Core Team. 2014. nlme: linear and nonlinear mixed effects models. $\mathrm{R}$ package version 3.1-117. https://cran.r-project.org/web/packa ges/nlme/index.html

Portner, H. O., and A. P. Farrell. 2008. Physiology and climate change. Science 322:690-692.

Post, E., C. Pedersen, C. C. Wilmers, and M. C. Forchhammer. 2008. Warming, plant phenology and the spatial dimension of trophic mismatch for large herbivores. Proceedings: Biological Sciences 275:2005-2013.

R Core Team. 2018. R: A language and environment for statistical computing. R Foundation for Statistical Computing, Vienna, Austria.

Raithel, J. D., M. J. Kauffman, and D. H. Pletscher. 2007. Impact of spatial and temporal variation in calf survival on the growth of elk populations. Journal of Wildlife Management 71:795-803.

Renecker, L. A., and C. C. Schwartz 2007. Food habits and feeding behavior. Pages 403-440 in A. W. Franzmann and C. C. Schwartz, editors. Ecology and management of the North American moose. University Press of Colorado, Boulder, Colorado, USA.

Riney, T. 1955. Evaluating condition of free-ranging red deer (Cervus elaphus) with special reference to New Zealand. New Zealand Journal of Science and Technology B. General Research 36:429-463.

Robert, C. P., G. Casella, and G. Casella 2010. Introducing Monte Carlo methods with R. Springer, Berlin, Germany.

Ruprecht, J. S., K. R. Hersey, K. Hafen, K. L. Monteith, N. J. DeCesare, M. J. Kauffman, and D. R. MacNulty. 2016. Reproduction in moose at their southern range limit. Journal of Mammalogy 97:1355-1365.

Schwartz, C. C., W. L. Regelin, and A. Franzmann. 1984. Seasonal dynamics of food intake in moose. Alces 20:223-244.

Seaton, C. T., T. F. Paragi, R. D. Boertje, K. Kielland, S. DuBois, and C. L. Fleener. 2011. Browse biomass removal and nutritional condition of moose Alces alces. Wildlife Biology 17:55-66.

Severud, W. J., G. D. Giudice, T. R. Obermoller, T. A. Enright, R. G. Wright, and J. D. Forester. 2015. Using GPS collars to determine parturition and cause-specific mortality of moose calves. Wildlife Society Bulletin 39:616-625.

Sikes, R. S., W. L. Gannon, and M. Amer Soc. 2011. Guidelines of the American Society of Mammalogists for the use of wild mammals in research. Journal of Mammalogy 92:235-253.

Stearns, S. C. 1992. The evolution of life histories. OUP Oxford, Oxford, UK 
Stephenson, T. R., K. J. Hundertmark, C. C. Schwartz, and V. Van Ballenberghe. 1998. Predicting body fat and body mass in moose with ultrasonography. Canadian Journal of Zoology 76:717-722.

Stevens, D. L., and A. R. Olsen. 2004. Spatially balanced sampling of natural resources. Journal of the American Statistical Association 99:262-278.

Stewart, K. M., R. T. Bowyer, B. L. Dick, B. K. Johnson, and J. G. Kie. 2005. Density-dependent effects on physical condition and reproduction in North American elk: an experimental test. Oecologia 143:85-93.

Taberlet, P., S. Griffin, B. Goossens, S. Questiau, V. Manceau, N. Escaravage, L. P. Waits, and J. Bouvet. 1996. Reliable genotyping of samples with very low DNA quantities using PCR. Nucleic Acids Research 24:3189-3194.

Taillon, J., P. S. Barboza, and S. D. Cote. 2013. Nitrogen allocation to offspring and milk production in a capital breeder. Ecology 94:1815-1827.

Thornton, P. E., M. M. Thornton, B. W. Mayer, N. Wilhelmi, Y Wei, R. Devarakonda, and R. B. Cook. 2014. Daymet: Daily
Surface Weather Data on a 1-km Grid for North America, Version 2. https://daymet.ornl.gov/

Toweill, D. E., and G. Vecellio. 2004. Shiras moose in Idaho: status and management. Alces 40:33-43.

Vartanian, J. M. 2011. Habitat condition and the nutritional quality of seasonal forage and diets: demographic implications for a declining moose population in northwest Wyoming, USA. University of Wyoming, Laramie, Wyoming, USA.

Waits L. P., G. Luikart, and P. Taberlet. 2001. Estimating the probability of identity among genotypes in natural populations: cautions and guidelines. Molecular Ecology 10(1):249 -256. https://doi.org/10.1046/j.1365-294x.2001.01185.x.

Wasser, S. K., S. L. Monfort, and D. E. Wildt. 1991. Rapid extraction of faecal steroids for measuring reproductive cyclicity and early pregnancy in free-ranging yellow baboons (Papio cynocephalus cynocephalus). Journal of Reproduction and Fertility 92:415-423.

Wolfe, M. L., K. R. Hersey, and D. C. Stoner. 2010. A history of moose management in Utah. Alces 46:37-52.

SUPPORTING INFORMATION

Additional supporting information may be found online at: http://onlinelibrary.wiley.com/doi/10.1002/eap.2299/full

Data Availability

Data used in this study are available on the Dryad Digital Repository (Jesmer et al. 2020): https://doi.org/10.5061/dryad. z8w9ghx9s. 